\title{
Estimation of the Diesel Particulate Filter Soot Load Based on an Equivalent Circuit Model
}

\author{
Yanting Du, Guangdi Hu *, Shun Xiang ${ }^{(\mathbb{D}}$, Ke Zhang, Hongxing Liu and Feng Guo \\ School of Mechanical Engineering, Southwest Jiaotong University, Chengdu 610031, China; \\ duyanting_swjtu@163.com (Y.D.); xiang_shun_swjtu@163.com (S.X.); kezhang99@gmail.com (K.Z.); \\ lhongxing1219@163.com (H.L.); fguo@my.swjtu.edu.cn (F.G.) \\ * Correspondence: ghu@swjtu.edu.cn
}

Received: 31 January 2018; Accepted: 21 February 2018; Published: 23 February 2018

\begin{abstract}
In order to estimate the diesel particulate filter (DPF) soot load and improve the accuracy of regeneration timing, a novel method based on an equivalent circuit model is proposed based on the electric-fluid analogy. This proposed method can reduce the impact of the engine transient operation on the soot load, accurately calculate the flow resistance, and improve the estimation accuracy of the soot load. Firstly, the least square method is used to identify the flow resistance based on the World Harmonized Transient Cycle (WHTC) test data, and the relationship between flow resistance, exhaust temperature and soot load is established. Secondly, the online estimation of the soot load is achieved by using the dual extended Kalman filter (DEKF). The results show that this method has good convergence and robustness with the maximal absolute error of $0.2 \mathrm{~g} / \mathrm{L}$ at regeneration timing, which can meet engineering requirements. Additionally, this method can estimate the soot load under engine transient operating conditions and avoids a large number of experimental tests, extensive calibration and the analysis of complex chemical reactions required in traditional methods.
\end{abstract}

Keywords: diesel particulate filter; soot load estimation; flow resistance; equivalent circuit model; dual extended Kalman filter

\section{Introduction}

Particulate matter (PM) is the main emission pollutant of diesel engines and it is harmful to human health [1]. As emission regulations become more stringent, diesel engines must be equipped with aftertreatment systems to meet emission requirements [2,3]. The diesel particulate filter (DPF) is the most effective technique to reduce PM emissions [4]; it can capture more than 90\% of PM [5-7] with many parallel channels inserted at both ends to force the exhaust gases through the porous ceramic walls [8]. However, with the gradual accumulation of PM in the DPF, the exhaust manifold back pressure of the engine gradually increases, which leads to the decline of engine efficiency, and increases fuel consumption [9]. As a result, it is necessary to periodically or continuously remove PM, which is called DPF regeneration [10]. There are basically two approaches for DPF regeneration: passive regeneration and active regeneration. Triggering a DPF regeneration at the right timing is a challenging task that requires an accurate estimation of the soot load. If the regeneration frequency is too high, the fuel economy of the engine will be worsened [11] and the life-span of the DPF will be reduced. If the regeneration frequency is too low, there will be too much soot particle accumulation in the DPF, which will result in poor engine performance. In particular, a large amount of soot accumulation in the DPF can easily elevate a higher temperature gradient leading to DPF body cracks [12]. In a catalytic DPF, the accurate estimation of soot load plays a critical role in determining the optimal conditions of soot-catalyst contact $[13,14]$. Therefore, it is important to improve the accuracy of soot load estimation and accurately judge the regeneration timing $[15,16]$. Some research has been conducted examining the indirect method of soot load estimation. In $[17,18]$, the method of estimating the soot load based on the 
soot load model is studied to address the relatively poor accuracy of soot estimation at a lower exhaust volumetric flow. The authors [19] establish a mathematical model to calculate the soot load, which is based on steady-state loading characterization experiments. The relationship between the pressure drop in the DPF and the soot load has been studied [20,21], where the DPF soot load was obtained from the pressure drop under different flow resistances. However, engine exhaust gas is a pulsating airflow in nature, which is intensified under diesel transient operating conditions. As a result, the measured values of the pressure sensor are quite noisy, which leads to a significant deviation to determining the soot load if simply using the measurement signals of the DPF differential pressure sensor.

In this paper, a novel method for estimation of the DPF soot load based on a DPF equivalent circuit model is proposed, where the resistance affected by soot load can be estimated online with measurement parameters (exhaust flow, exhaust temperature and DPF pressure drop) in dual extended Kalman filter (DEKF). Additionally, the relationship between exhaust temperature, resistance and soot load is established with the least square method and fitting method, so that the soot load can be estimated. The equivalent circuit model is also validated by the diesel engine transient tests based on the World Harmonized Transient Cycle (WHTC) test cycle in the Euro VI emission standard. The results show that the proposed method overcomes the difficulty of accurately estimating the soot load online under diesel engine transient operating conditions and improves the estimation accuracy of the soot load, while avoiding the shortcoming of a large number of experimental tests and analyses of complex chemical reactions required in traditional methods.

\section{Test System}

To verify this method, the test system is built. The diesel engine used is an electronically controlled high pressure common rail diesel engine with a high pressure common rail electric fuel injection system of Bosch. The technical parameters are shown in Table 1. The speed and torque of the engine are measured with a CW440 hydraulic dynamometer, the pressure drop of the DPF is measured with a HX-L61 differential pressure sensor, and the soot in the DPF is weighed with a HJ-33KSE weigh scale. The test is based on the WHTC. The pressure drop of the DPF, exhaust volume flow and exhaust temperature are recorded during the test, and the soot load is weighed when the test is completed.

Table 1. Parameters of the engine.

\begin{tabular}{ccc}
\hline Parameter & Unit & Value \\
\hline Intake type & $/$ & Pressuring intercool \\
Cylinder number & $/$ & 6 \\
Cylinder diameter $\times$ piston travel & $\mathrm{mm}$ & $108 \times 130$ \\
Displacement & $\mathrm{L}$ & 7.14 \\
Rated power & $\mathrm{kW}$ & 176 \\
Rated speed & $\mathrm{rpm}$ & 2300 \\
Maximum torque & $\mathrm{N} \cdot \mathrm{m}$ & 1000 \\
Speed at maximum torque & $\mathrm{rpm}$ & 1700 \\
Idle speed & $\mathrm{rpm}$ & $600 \pm 50$ \\
\hline
\end{tabular}

The DPF is made of cordierite; the characteristic parameters are shown in Table 2. 
Table 2. Parameters of the diesel particulate filter (DPF).

\begin{tabular}{ccc}
\hline Parameter & Unit & Value \\
\hline Material & $/$ & Cordierite \\
Size (diameter $\times$ length) & $\mathrm{mm}$ & $229 \times 275$ \\
Cell density & Cell $/$ inch $^{2}$ & 200 \\
Volume & $\mathrm{L}$ & 11.34 \\
Wall thickness & $\mathrm{mm}$ & 0.305 \\
Thermal conductivity & $\mathrm{W} /(\mathrm{m} \cdot \mathrm{K})$ & 1.8 \\
Specific heat capacity & $\mathrm{J} /(\mathrm{kg} \cdot \mathrm{K})$ & 1120 \\
\hline
\end{tabular}

\section{Equivalent Circuit Model}

In the electric-fluid analogy, flow response in the DPF is modeled by an electric circuit [22] based on the transient equations between flow and the electric circuit, as shown in Figure 1. The theoretical basis for the establishment of the model is as follows.

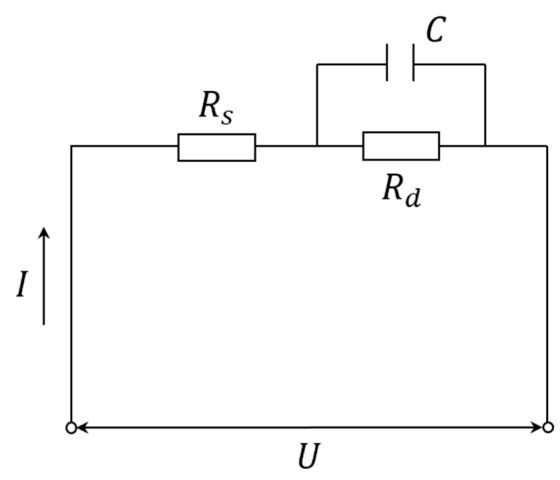

Figure 1. Diesel particulate filter equivalent circuit model.

The following relationship reads [23],

$$
Q=\frac{\Delta P}{R_{0}}
$$

Q-flow,

$\Delta P$-pressure drop,

$R_{0}$-flow resistance of the unit area.

Equation (1) indicates that the exhaust gas flow passing through the DPF will be affected by the flow resistance of the DPF which leads to a pressure drop across the DPF. This can be analogous to the electric current passing through the circuit that is affected by the electric resistance which leads to a voltage drop across the circuit. Due to the fact that the exhaust gas can be viewed as compressible gas in the DPF, the capacitance in the electric circuit that represents the electric charge storage can be analogized by the compressibility of the gas flow. As a result, the following analogy relationship between the gas flow in the DPF and the equivalent electric circuit can be built:

1. Pressure drop $\triangle P$ of DPF is equivalent to $U$, the voltage across the circuit.

2. Exhaust volume flow $Q$ is equivalent to the circuit current $I$.

3. The gas flow resistance is equivalent to circuit resistance $R_{S}$ and $R_{d}$.

4. The coefficient of compressibility of the gas flow in the DPF is equivalent to the circuit capacitance $C$.

There will be two kinds of pressure drop when the exhaust gas passes through the DPF: the inertial pressure drop and the porous media and friction pressure drop. According to the above relationship, it can be assumed that the inertial pressure drop caused by the inlet and outlet of the DPF is equivalent 
to the circuit resistance $R_{s}$ shown in Figure 1. Taking the impact of temperature $T$ on the flow resistance into account [24], $R_{S}$ can be described as

$$
R_{s}=a_{0}+a_{1} T+a_{2} T^{2}
$$

in which, $a_{0}, a_{1}$ and $a_{2}$ are constant parameters.

Likewise, the exhaust gas flow resistance caused by the porous media and friction pressure drop, including the influence of soot load in the DPF [25], is equivalent to the circuit resistance $R_{d}$. Taking into account the impact of temperature and soot load on the flow resistance $R_{d}, R_{d}$ can be described as

$$
R_{d}=b+b_{0}+b_{1} T+b_{2} T^{2}
$$

where $b_{0}, b_{1}$ and $b_{2}$ are constant parameters, and $\mathrm{b}$ varies with $\mathrm{m}$, which is affected by filtration and passive regeneration, so $\mathrm{b}$ can be described as

$$
b=f(m)
$$

The capacitor $C$ is connected in parallel across the resistance $R_{d}$. The compressibility of the exhaust gas in the DPF is related to the nature of the exhaust gas, as well as the structure and the volume of the DPF, so $C$ will change with the soot loads [26]. Meanwhile, the capacitance $C$ operates as a filter to the transient operation effects of the exhaust gas flow that leads to the accurate estimation of the flow resistance $R_{d}$ related to the soot load accumulated within the DPF.

Referring to Figure 1, the mathematical model of the equivalent circuit model can be described as

$$
\begin{gathered}
U=U_{s}+U_{d}=I R_{s}+U_{d} \\
I=C \frac{\mathrm{d} U_{d}}{\mathrm{~d} t}+\frac{U_{d}}{R_{d}} \\
\frac{\mathrm{d} U_{d}}{\mathrm{~d} t}+\frac{U_{d}}{R_{d} C}=\frac{I}{C}
\end{gathered}
$$

According to Equations (5)-(7), the following relationship can be obtained,

$$
\frac{\mathrm{d} U}{\mathrm{~d} t}+\frac{U}{R_{d} C}=R_{s} \cdot \frac{\mathrm{d} I}{\mathrm{~d} t}+\frac{R_{d}+R_{s}}{R_{d} C} \cdot I
$$

The discretization form of Equation (8) can be expressed as

$$
U(k)=\left(1-\frac{\Delta T}{R_{d} C}\right) \cdot U(k-1)+R_{s} I(k)+\left(\frac{\left(R_{d}+R_{s}\right) \Delta T}{R_{d} C}-R_{s}\right) \cdot I(k-1)
$$

where $\Delta T$ is the sampling time, and $R_{s}\left(a_{0}, a_{1}, a_{2}\right), R_{d}\left(b, b_{0}, b_{1}, b_{2}\right)$ and $C$ are parameters to be determined. The measured data of the pressure drop across the DPF $\Delta P$, the volume flow $Q$ and the temperature $T$ of the exhaust gas can be utilized for parameter identification.

\section{Identification of Model Parameters}

\subsection{Parameter Identification Based on the Least Squares Method}

Here, the least square method [27] is chosen for parameter identification. The input and output characteristics of the system are considered.

A typical difference equation can be described as

$$
y(t)=\varnothing^{T}(t) \theta+\varepsilon(t)
$$


where $\theta$ is the parameter vector to be estimated,

$$
\theta=\left[d_{1}, d_{2}, \cdots, d_{n}\right]^{T}
$$

$y(t)$ is the observed value at time $t, \varepsilon(t)$ is white noise with zero mean, whose variance is greater than zero and $\varnothing^{T}(t)$ is the vector of the form,

$$
\varnothing^{T}(t)=[y(t-1), \cdots, y(t-n)]
$$

where $y(t-1)$ is the observed value at the previous time $(t-1)$. Then, $\theta$ can be estimated by a recursive process,

$$
\theta(t+1)=\theta(t)+F(k)\left[y(t+1)-\varnothing^{T}(t+1) \theta(t)\right]
$$

where

$$
\begin{gathered}
F(k)=\frac{P(t) \varnothing(t+1)}{1+\varnothing^{T}(t+1) P(t) \varnothing(t+1)} \\
P(t+1)=P(t)-\frac{P(t) \varnothing(t+1) \varnothing^{T}(t+1) P(t)}{1+\varnothing^{T}(t+1) P(t) \varnothing(t+1)}
\end{gathered}
$$

where, $\theta(t)$ is the parameter vector to be identified, $F(k), \phi(t+1), P(t)$ is the gain matrix, the observation matrix, and the covariance matrix, respectively.

\subsection{Results of Parameter Identification}

The equivalent circuit model of the DPF is established in the MATALB/Simulink simulation environment. Parameter identification is conducted with test data collected from the WHTC cycle of the DPF. The WHTC cycle is a globally consistent engine transient test cycle with a $1800 \mathrm{~s}$ test period. After 20 cycles, the soot load is weighed as $4 \mathrm{~g} / \mathrm{L}$, and the soot loads at the end of the 1st, 4th and 15th cycle are weighed as $0.2 \mathrm{~g} / \mathrm{L}, 0.8 \mathrm{~g} / \mathrm{L}$ and $3 \mathrm{~g} / \mathrm{L}$ respectively. As the operation conditions of all the cycles are the same, it can be concluded that the accumulated soot load per cycle is $0.2 \mathrm{~g} / \mathrm{L}$. As a result, the soot loads at the beginning of the $1 \mathrm{st}, 4 \mathrm{th}, 15 \mathrm{th}$ and 20 th cycle are weighed as $0 \mathrm{~g} / \mathrm{L}, 0.6 \mathrm{~g} / \mathrm{L}$, $2.8 \mathrm{~g} / \mathrm{L}$ and $3.8 \mathrm{~g} / \mathrm{L}$, which are chosen for parameter identification.

The volume flow and temperature of the exhaust gas are taken as the input while the pressure drop is taken as the output. It is assumed that $b$ stays the same for $30 \mathrm{~s}$, because the soot load changes little within $30 \mathrm{~s}$. The least squares algorithm is used to identify parameters; this follows two steps,

Step 1: A set of parameters $a_{0}, a_{1}$ and $a_{2}$ of $R_{s}, b_{0}, b_{1}$ and $b_{2}$ of $R_{d}$ and $C$ are identified with the test data of the first cycle.

Step 2: With the parameters $a_{0}, a_{1}$ and $a_{2}$ of $R_{s}$ and $b_{0}, b_{1}$ and $b_{2}$ of $R_{d}$ obtained in Step 1 , a set of parameters $b$ and $C$ are identified with the test data of different soot loads of the 4 th, 15 th, and 20th cycles.

\begin{tabular}{|c|c|c|c|c|c|c|c|c|}
\hline Soot Load & $0 \mathrm{~g} / \mathrm{L}$ & $0.2 \mathrm{~g} / \mathrm{L}$ & $0.6 \mathrm{~g} / \mathrm{L}$ & $0.8 \mathrm{~g} / \mathrm{L}$ & $2.8 \mathrm{~g} / \mathrm{L}$ & $3 \mathrm{~g} / \mathrm{L}$ & $3.8 \mathrm{~g} / \mathrm{L}$ & $4 \mathrm{~g} / \mathrm{L}$ \\
\hline$b$ & 16.02 & 16.36 & 22.55 & 23.00 & 30.64 & 31.88 & 32.66 & 32.88 \\
\hline C & 0.088 & 0.085 & 0.078 & 0.076 & 0.055 & 0.054 & 0.051 & 0.050 \\
\hline
\end{tabular}

Identification results are shown in Tables 3 and 4.

Table 3. Parameter identification results.

\begin{tabular}{ccccccc}
\hline Soot Load & $\boldsymbol{a}_{\mathbf{0}}$ & $\boldsymbol{a}_{\mathbf{1}}$ & $\boldsymbol{a}_{\mathbf{2}}$ & $\boldsymbol{b}_{\mathbf{0}}$ & $\boldsymbol{b}_{\mathbf{1}}$ & $\boldsymbol{b}_{\mathbf{2}}$ \\
\hline $0 \mathrm{~g} / \mathrm{L}$ & 5.0274 & -0.033922 & $9.6847 \times 10^{-5}$ & -2.268 & 0.01423 & $-2.071 \times 10^{-5}$ \\
\hline
\end{tabular}

Table 4. Parameter identification results of $R_{d}$ and $C$. 
With the results in Table 4, the relationship between $b$ and $m$ is obtained with the fitting method, which is shown in Figure 2 and Equation (16), and the standard deviation of which is only 0.61. To verify the $b-m$ relationship, the values of $b$ are identified every $30 \mathrm{~s}$, so that the simulation values of the output are obtained, which can be compared with the test values, shown in Figure 3.

$$
b=6.09 \ln 55.71 m
$$

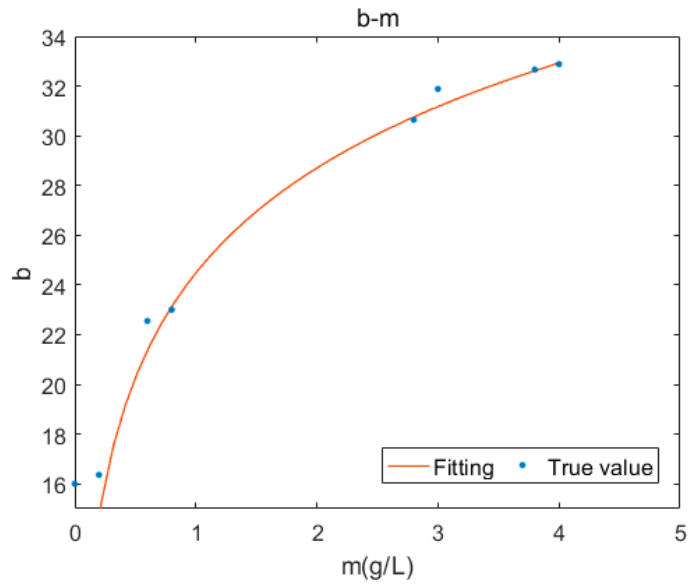

Figure 2. The relationship between $b$ and $m$.

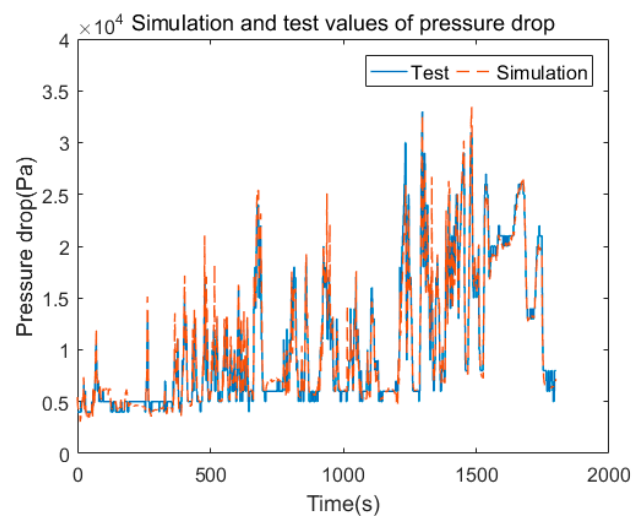

(a)

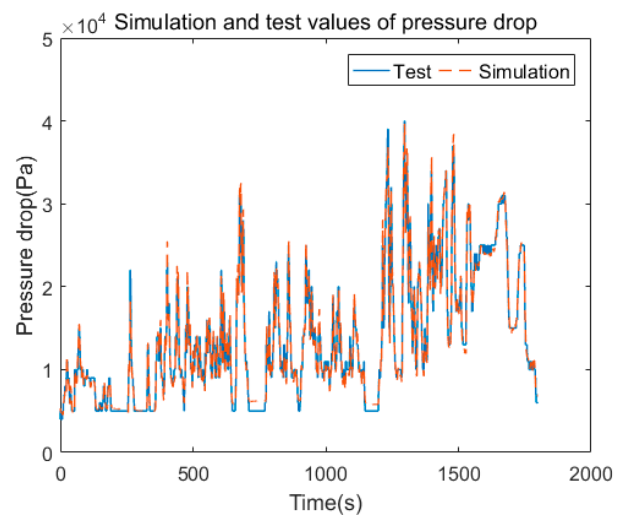

(c)

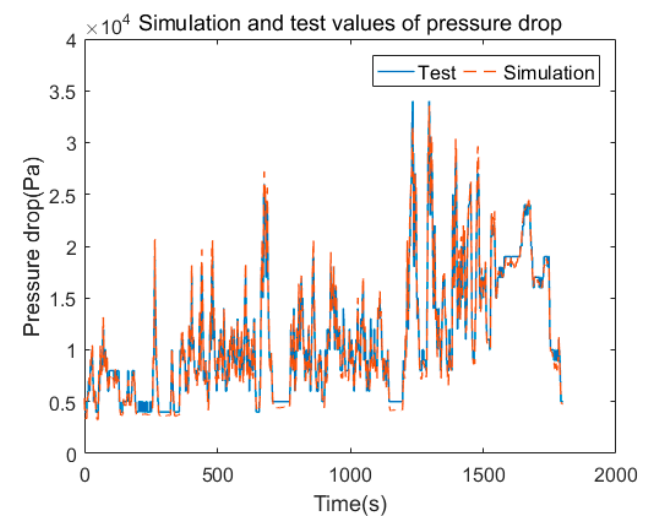

(b)

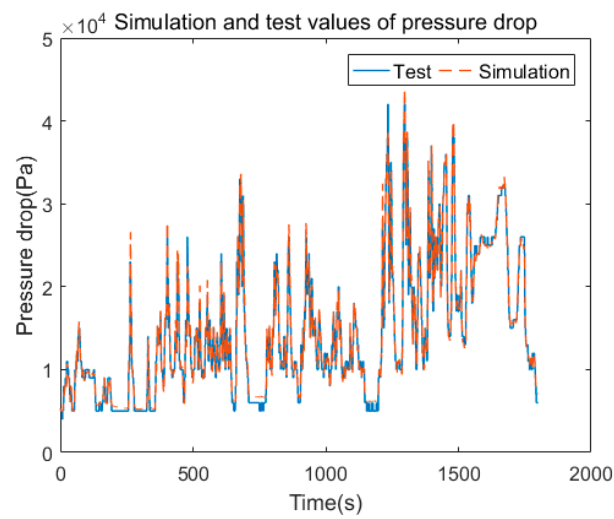

(d)

Figure 3. Comparison between simulation and test values of the pressure drop: (a) Pressure drop under the 1st cycle; (b) Pressure drop under the 4th cycle; (c) Pressure drop under the 15th cycle; (d) Pressure drop under the 20th cycle. 
As shown in Figure 3, the standard deviations of the output pressure drops under different soot loads of the 1st, 4th, 15th, and 20th cycles are only $783 \mathrm{~Pa}, 568 \mathrm{~Pa}, 617 \mathrm{~Pa}$ and $633 \mathrm{~Pa}$ respectively, which verify the accuracy of the model. An $R_{d}-T$ map is shown in Figure 3 according to the results in Tables 3 and 4 . It can be seen that the flow resistance $R_{d}$ increases with the increase of soot load. The fast increasing curves of $R_{d}-T$ from $0.0 \mathrm{~g} / \mathrm{L}$ to $0.8 \mathrm{~g} / \mathrm{L}$ and $3 \mathrm{~g} / \mathrm{L}$ matches well with the characteristics of the deep bed trapping stage in the DPF, and the slow increasing curves of $R_{d}-T$ from $3 \mathrm{~g} / \mathrm{L}$ and $4 \mathrm{~g} / \mathrm{L}$ are in line with the cake capture characteristics.

\section{Online Estimation of Soot Load}

\subsection{Dual Extended Kalman Filter}

During the actual vehicle driving, it is of great importance to estimate the soot load online. In this paper, the dual extended Kalman filter is used to carry out the online estimation of the soot load, where state and parameter can be estimated at the same time with the input and output observation data of the system.

Calculation with the dual extended Kalman filter [28]:

1. The equations of the system are as follows,

$$
\begin{gathered}
x_{k}=A x_{k-1}+B u_{k-1}+w_{k-1} \\
\theta_{k}=\theta_{k-1}+r_{k-1} \\
y_{k}=C x_{k}+D u_{k}+v_{k}
\end{gathered}
$$

where $x$ is the system state, $u$ is the system input, $w$ is the process noise, $\theta$ is the system parameter, $r$ is the process noise, $y$ is the system output, and $v$ is the measurement noise.

2. The calculation process is as follows:

Initialization, for $k=0$,

$$
\begin{gathered}
\hat{\theta}_{0}=E\left[\theta_{0}\right], P_{\theta_{0}}=E\left[\left(\theta_{0}-\hat{\theta}_{0}\right)\left(\theta_{0}-\hat{\theta}_{0}\right)^{T}\right] \\
\hat{x}_{0,0}=E\left[x_{0}\right], P_{x_{0}}=E\left[\left(x_{0}-\hat{x}_{0}\right)\left(x_{0}-\hat{x}_{0}\right)^{T}\right]
\end{gathered}
$$

For $k \in\{1, \cdots, \infty\}$,

Step 1: time-update equations for parameter

$$
\begin{gathered}
\hat{\theta}_{k}^{-}=\hat{\theta}_{k-1} \\
P_{k, \theta}^{-}=P_{k-1, \theta}^{+}+Q_{\theta}
\end{gathered}
$$

Step 2: time-update equations for state

$$
\begin{gathered}
\hat{x}_{k}^{-}=A_{k-1} \hat{x}_{k-1}^{+}+B_{k-1} u_{k-1} \\
P_{k, x}^{-}=A_{k-1} P_{k-1, x}^{+} A_{k-1}^{T}+Q_{x}
\end{gathered}
$$

Step 3: measurement-update equations for state

$$
\begin{gathered}
K_{k, x}=P_{k, x}^{-} C_{k, x}^{T}\left(C_{k, x} P_{k, x}^{-} C_{k, x}^{T}+R_{x}\right)^{-1} \\
\hat{x}_{k}^{+}=\hat{x}_{k}^{-}+K_{k, x}\left(y_{k}-y_{k-1}\right) \\
P_{k, x}^{+}\left(I-K_{k, x} C_{k, x}\right) P_{k, x}^{-}
\end{gathered}
$$


Step 4: measurement-update equations for parameter

$$
\begin{gathered}
K_{k, \theta}=P_{k, \theta}^{-} C_{k, \theta}^{T}\left(C_{k, \theta} P_{k, \theta}^{-} C_{k, \theta}^{T}+R_{\theta}\right)^{-1} \\
\hat{\theta}_{k}^{-}=\hat{\theta}_{k-1}+K_{k, \theta}\left(y_{k}-y_{k-1}\right) \\
P_{k, \theta}^{+}\left(I-K_{k, \theta} C_{k, \theta}\right) P_{k, \theta}^{-}
\end{gathered}
$$

Applying the above algorithm to the model of this paper, the state equations are as follows,

$$
\begin{aligned}
U_{d, k+1}= & \left(1-\frac{\Delta T}{R_{d} C}\right) \cdot U_{d, k}+\frac{\Delta T}{C} \cdot I_{k} \\
& R_{d, k+1}=R_{d, k}+r_{k} \\
& U_{k}=U_{d, k}+R_{s} \cdot I_{k}
\end{aligned}
$$

where $A_{k}=1-\frac{\Delta T}{R_{d} C}, B_{k}=\frac{\Delta T}{C}, C_{k, x}=1, C_{k, \theta}=\left.\frac{d G\left(\hat{x}_{k}, \theta, u_{k}\right)}{d \theta}\right|_{\theta=\hat{\theta}_{k}^{-}}$.

In this model, $I$ is the input, $U$ is the output, $U_{d}$ is the state and $R_{d}$ is the parameter. With the input and output data, the optical estimations of $U_{d}$ and $R_{d}$ can be obtained in every sampling step with the iterative calculation process above.

In addition, the value of $R_{S}$ is determined according to Table 3 and $C$ is determined by interpolation of the values of $C$ under different soot loads in Table 4 . The initial value of $R_{d}$ is equal to the last estimated value. Online estimation of the $R_{d}$ value is carried out with the DEKF method using the test data obtained under vehicle transient operating conditions. Eventually, according to $R_{d}$ and exhaust temperature $T$, the soot load is obtained according to the $b-m$ curve. The estimation process is shown in Figure 4.

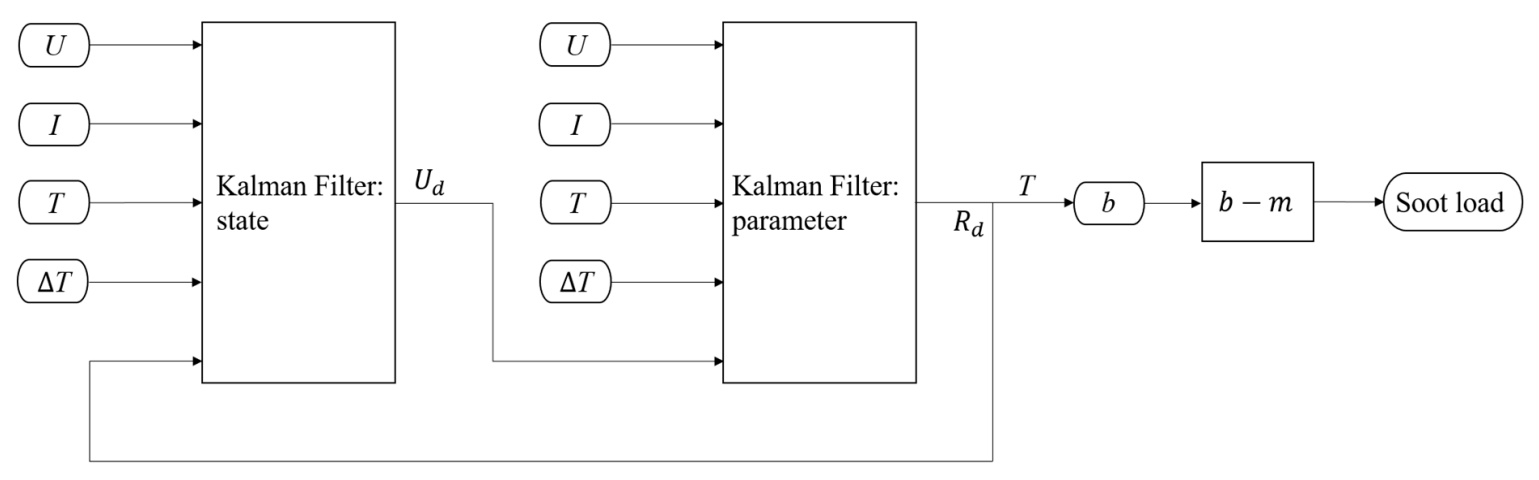

Figure 4. Online estimation process of the soot load.

\subsection{Verification and Discussion}

The dual extended Kalman filter approach is implemented in MATALB/Simulink, and the simulation results are compared with the results verified in Section 4.2. The estimation results of soot load are shown in Figure 5 compared with the test values. After calculation, the error is shown in Table 5. 


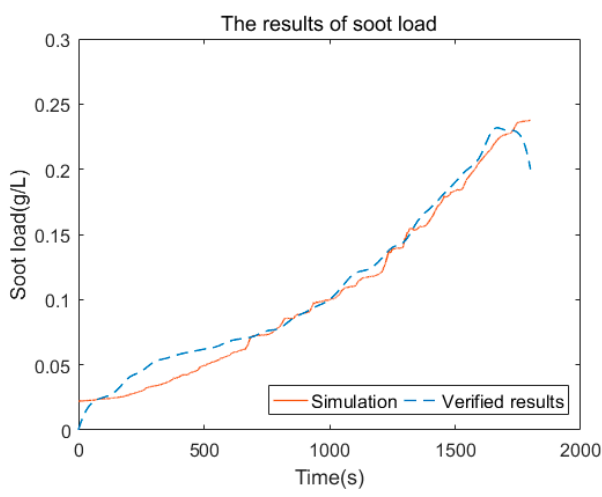

(a)

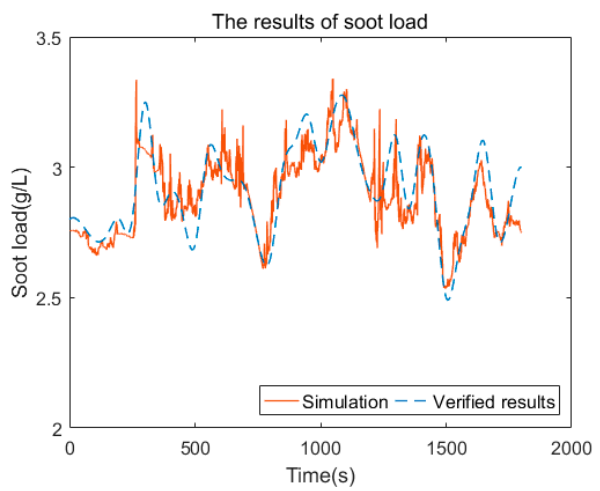

(c)

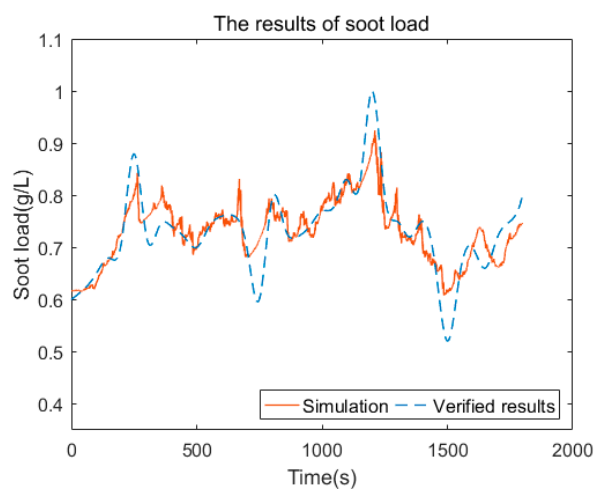

(b)

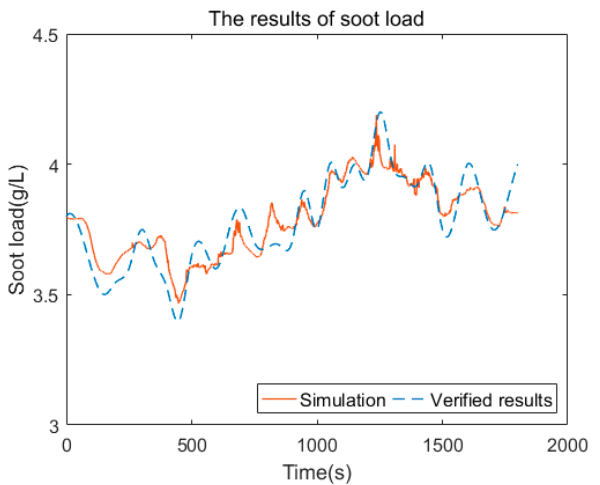

(d)

Figure 5. The results of the soot load: (a) Soot load of the 1st cycle; (b) Soot load of the 4th cycle; (c) Soot load of the 15th cycle; (d) Soot load of the 20th cycle.

Table 5. Error of the results.

\begin{tabular}{ccc}
\hline Cycle & Maximum Relative Error & Maximum Absolute Error \\
\hline 1 & $20 \%$ & $0.04 \mathrm{~g} / \mathrm{L}$ \\
4 & $12.5 \%$ & $0.10 \mathrm{~g} / \mathrm{L}$ \\
15 & $8 \%$ & $0.24 \mathrm{~g} / \mathrm{L}$ \\
20 & $5 \%$ & $0.20 \mathrm{~g} / \mathrm{L}$ \\
\hline
\end{tabular}

In addition, when the soot load is not accumulated from $0 \mathrm{~g} / \mathrm{L}$, or when the initial value is wrong, the anti-interference ability of the method should be verified. When the wrong initial value is set, which is very different from the real value, the method must be verified, as shown in Figure 6.

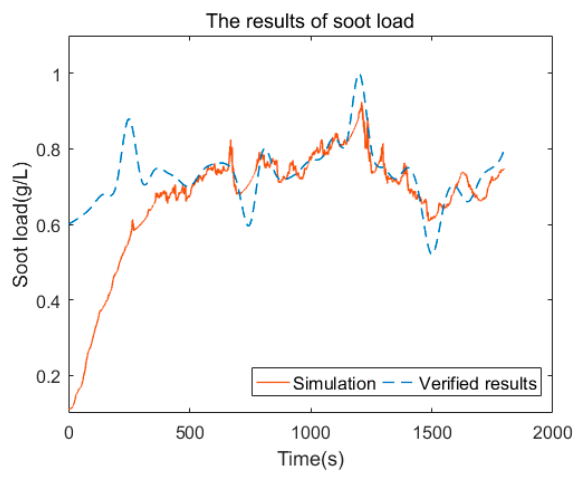

(a)

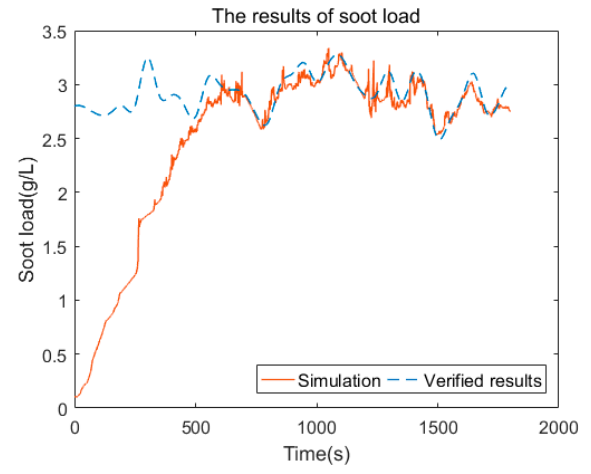

(b)

Figure 6. Cont. 


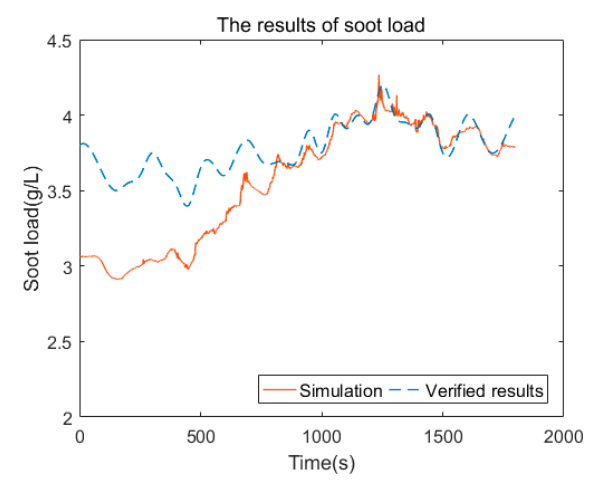

(c)

Figure 6. The results of the soot load with an incorrect initial value: (a) Soot load of the 4th cycle; (b) Soot load of the 15th cycle; (c) Soot load of the 20th cycle.

Analysis of the simulation results is as follows,

In the traditional method, the effect of engine transient operation on the test signals cannot be effectively dealt with, which leads to the inaccuracy of the results. In this paper, the DEKF method is used to filter the test signals to make the results more accurate.

In the case of correct initial values, the error of $m$ is small. The maximum absolute error of $0.2 \mathrm{~g} / \mathrm{L}$ at the regeneration timing can meet the requirements of the project. In the process of soot load accumulation, the simulation also works well.

In the case of very inaccurate initial values, the soot load $m$ can converge quickly, showing good convergence and robustness, which makes sense for practical application.

\section{Conclusions}

In this paper, an online soot estimation method based on an equivalent circuit model is creatively proposed. The method mainly aims to estimate the soot load of the DPF online under transient operating conditions, and can eliminate the interference caused by engine transient operation effects, showing good convergence and robustness. Its maximum absolute error is $0.2 \mathrm{~g} / \mathrm{L}$ at regeneration timing, which can meet the engineering requirements, and optimize the regeneration of catalytic DPFs by maximizing the soot-catalyst contact in the filters $[29,30]$. The proposed method avoids the shortcoming of a large number of experiments and avoids the analysis of complex chemical reactions required in traditional methods.

Acknowledgments: This work was supported by Application and Industrialization of Light Diesel Vehicle Aftertreatment Technology under the Standard of China IV Emission Project (Grant No. 2015CC0003). Meanwhile, we would like to express our gratitude to the reviewers for their corrections and helpful suggestions.

Author Contributions: Yanting Du and Guangdi Hu proposed the idea; Yanting Du and Shun Xiang built the MATLAB/Simulink model; Ke Zhang conducted the tests and analyzed the data; Yanting Du wrote the first draft; Guangdi $\mathrm{Hu}$, Shun Xiang, Hongxing Liu and Feng Guo revised the paper.

Conflicts of Interest: The authors declare no conflict of interest.

\section{Nomenclature}

\section{Symbols}

$Q \quad$ exhaust volume flow, $\mathrm{m}^{3} / \mathrm{h}$

$\Delta P \quad$ pressure drop of diesel particulate filter, $\mathrm{Pa}$

$R_{0} \quad$ flow resistance of the unit area, $\mathrm{Pa} \cdot \mathrm{h} / \mathrm{m}^{3}$

$U \quad$ voltage across the circuit

I electric current

T temperature of the exhaust gas, ${ }^{\circ} \mathrm{C}$

$R_{S} \quad$ resistance equivalent to the local flow resistance 
$R_{d} \quad$ resistance equivalent to the exhaust gas flow resistance caused by the friction drag

$U_{s} \quad$ voltage across $R s$

$U_{d} \quad$ voltage across $R d$

C circuit capacitance

$t \quad$ simulink time, $\mathrm{s}$

$\Delta T \quad$ sampling time, $\mathrm{s}$

$k$ time step index

$m \quad$ mass of the soot load, $\mathrm{g} / \mathrm{L}$

$a_{0}, a_{1}, a_{2} \quad$ parameters in $R_{S}$

$b, b_{0}, b_{1}, b_{2} \quad$ parameters in $R_{d}$

y observed value

$\theta \quad$ parameter

$\varnothing^{T} \quad$ vector of the observed value

$F \quad$ gain matrix

$\phi \quad$ observation matrix

$P \quad$ covariance matrix

$x \quad$ system state

$u \quad$ system input

$w \quad$ process noise

$r \quad$ process noise

y system output

$v \quad$ measurement noise

K Kalman gain

\section{Subscripts, superscripts}

$k$ time step index

- estimation value

$+\quad$ posteriori estimation value

Abbreviations

$\begin{array}{ll}\text { DEKF } & \text { dual extended Kalman filter } \\ \text { DPF } & \text { diesel particulate filter } \\ \text { PM } & \text { particulate matter } \\ \text { WHTC } & \text { World Harmonized Transient Cycle }\end{array}$

\section{References}

1. Kuwahara, T.; Nishii, S.; Kuroki, T.; Okubo, M. Complete regeneration characteristics of diesel particulate filter using ozone injection. Appl. Energy 2013, 111, 652-656. [CrossRef]

2. Chen, P.; Wang, J. Control-oriented model for integrated diesel engine and aftertreatment systems thermal management. Control Eng. Pract. 2014, 22, 81-93. [CrossRef]

3. Brahma, A. Modeling and Observability Analysis of DPF Regeneration. In Proceedings of the ASME 2008 Dynamic Systems and Control Conference, Ann Arbor, MI, USA, 20-22 October 2008; pp. 49-55.

4. Liu, H.W.; Yao, G.T.; Jiang, D.H.; Zi, X.Y.; Guo, Z.R. Design and Experimental Research on Evaporation-Type DPF Regenerative Burner. Appl. Mech. Mater. 2012, 229, 1025-1029. [CrossRef]

5. Schejbal, M.; Marek, M.; Kubíček, M.; Kočí, P. Modelling of diesel filters for particulates removal. Chem. Eng. J. 2009, 154, 219-230. [CrossRef]

6. Depcik, C.; Assanis, D. Simulating Area Conservation and the Gas-Wall Interface for One-Dimensional Based Diesel Particulate Filter Models. J. Eng. Gas Turbines Power 2008, 130, 062807. [CrossRef]

7. Valeria, D.S.; Almerinda, D.B. Modeling and simulation of soot combustion dynamics in a catalytic diesel particulate filter. Chem. Eng. Sci. 2015, 137, 69-78.

8. Zheng, H.; Keith, J.M. Averaging theory for diesel particulate filter regeneration. AIChE J. 2007, 53, $1316-1324$. [CrossRef]

9. Stamatelos, A.M. A review of the effect of particulate traps on the efficiency of vehicle diesel engines. Energy Convers. Manag. 1997, 38, 83-99. [CrossRef] 
10. Ogyu, K.; Yamakawa, T.; Ishii, Y.; Minoura, D.; Nagatsu, Y.; Kasuga, T.; Ohno, K. Soot loading estimation accuracy improvement by filtration layer forming on DPF and new algorithm of pressure loss measurement. SAE Tech. Pap. 2013, 2, 421-422.

11. Yamamoto, K.; Yamauchi, K. Numerical simulation of continuously regenerating diesel particulate filter. Proc. Combust. Inst. 2013, 34, 3083-3090. [CrossRef]

12. Ohno, K.; Shimato, K.; Toaka, N.; Hong, S.; Ninomiya, T.; Komori, T.; Salvat, O. Characterization of SiC-DPF for Passenger Car. SAE Technical Paper 2000-01-0185, 2000. Available online: https:/ /doi.org/10.4271/200001-0185 (accessed on 23 February 2018).

13. Valeria, D.S.; Gianluca, L.; Luciana, L.; Anna, S.; Almerinda, D.B. Catalytic diesel particulate filters with highly dispersed ceria: Effect of the soot-catalyst contact on the regeneration performance. Appl. Catal. B Environ. 2016, 197, 116-124.

14. Valeria, D.S.; Almerinda, D.B. Combined Effects of Soot Load and Catalyst Activity on the Regeneration Dynamics of Catalytic Diesel Par ticulate Filters. AlChE J. 2017. Available online: http: / / onlinelibrary.wiley. com/doi/10.1002/aic.16047/full (accessed on 23 February 2018).

15. Yu, M.; Dan, L.; Balakotaiah, V. Analysis of ignition in a diesel particulate filter. Catal. Today 2013, 216, 158-168. [CrossRef]

16. Chen, P.; Wang, J. Control-Oriented Modeling and Observer-Based Estimation of Solid and Gas Temperatures for a Diesel Engine Aftertreatment System. J. Dyn. Syst. Meas. Control 2012, 134, 061011. [CrossRef]

17. Tang, J.; Li, G.; Wang, Z.; Guo, S.; Zhang, J.; Tao, J. Construction and Experiment of DPF Soot Loading Model. Trans. Csice 2015, 33, 51-57.

18. Yan, M. Research on Model-based Particulate Matter Load. Master's Thesis, Jilin University, Changchun, China, June 2015.

19. Dabhoiwala, R.H.; Johnson, J.H.; Naber, J.; Bagley, S.T. A Methodology to Estimate the Mass of Particulate Matter Retained in a Catalyzed Particulate Filter as Applied to Active Regeneration and On-Board Diagnostics to Detect Filter Failures. SAE World Congress \& Exhibition, Detroit, MI, USA, 14 April 2008. Available online: https:/ / www.sae.org/publications/technical-papers/content/2008-01-0764/ (accessed on 23 February 2018).

20. Rose, D.; Boger, T. Different Approaches to Soot Estimation as Key Requirement for DPF Applications 2009-01-1262, SAE World Congress \& Exhibition, 20 April 2009. Available online: https: / www.sae.org/ publications / technical-papers/content/2009-01-1262/ (accessed on 23 February 2018).

21. Ohyama, N.; Nakanishi, T.; Daido, S. New Concept Catalyzed DPF for Estimating Soot Loadings from Pressure Drop 2008-01-0620, SAE World Congress \& Exhibition, 14 April 2008. Available online: https: / / www.sae.org/publications/technical-papers/content/2008-01-0620/ (accessed on 23 February 2018).

22. Zhang, Y.; Zhao, J.; Wang, P.; Skyllas-Kazacos, M.; Xiong, B.; Badrinarayanan, R. A comprehensive equivalent circuit model of all-vanadium redox flow battery for power system analysis. J. Power Sources 2015, 290, 14-24. [CrossRef]

23. Liu, H.L.; Wang, J.; Hwang, W.R. Flow Resistance of Viscoelastic Flows in Fibrous Porous Media. J. Non-Newtonian Fluid Mech. 2017, 246, 21-30. [CrossRef]

24. Tang, T.; Cao, D.; Zhang, J.; Zhao, Y.G.; Shuai, S.J. Experimental Study of Catalyzed Diesel Particulate Filter with Exhaust Fuel Injection System for Heavy-Duty Diesel Engines 2014-01-1496. SAE Tech. Pap. Available online: https: / / doi.org/10.4271/2014-01-1496 (accessed on 23 February 2018).

25. Yu, M.; Dan, L.; Balakotaiah, V. Analysis of flow distribution and heat transfer in a diesel particulate filter. Chem. Eng. J. 2013, 226, 68-78. [CrossRef]

26. Lai, Y.H.; Li, Y.; Rock, J.A. A novel full-field experimental method to measure the local compressibility of gas diffusion media. J. Power Sources 2010, 195, 3215-3223. [CrossRef]

27. Alonge, F.; D'Ippolito, F.; Raimondi, F.M. Least squares and genetic algorithms for parameter identification of induction motors. Control Eng. Pract. 2001, 9, 647-657. [CrossRef]

28. Xiong, R.; Sun, F.; Chen, Z.; He, H. A data-driven multi-scale extended Kalman filtering based parameter and state estimation approach of lithium-ion olymer battery in electric vehicles. Appl. Energy 2014, 113, 463-476. [CrossRef] 
29. Valeria, D.S.; Gianluca, L.; Luciana, L. Ceria-Coated Diesel Particulate Filters for Continuous Regeneration. AlChE J. 2017, 63, 3442-3449.

30. Valeria, D.S.; Almerinda, D.B. Operating Map for Regeneration of a Catalytic Diesel Particulate Filter. Ind. Eng. Chem. Res. 2016, 55, 11052-11061. 